\title{
Pengaruh Kualitas Restoran Terhadap Kepuasan Pelanggan Cengkir Heritage Resto And Coffe
}

\author{
Chriswardana Bayu Dewa \\ Universitas Bina Sarana Informatika \\ e-mail : chriswardana.chb@bsi.ac.id
}

\begin{abstract}
This study aims to examine the effect of restaurant quality on customer satisfaction. The research subjects were visitors to the restaurant Cengkir Heritage Resto and Coffe Yogyakarta. This study develops a theoretical model by making three hypotheses that will be tested using the Structural Equation Model (SEM) through the AMOS 18 application program. The survey method used in this study is distributing questionnaires to 120 respondents. This study uses non-probability sampling techniques, namely respondents randomly selected according to the purpose of the study. The results showed that restaurant quality consisting of service quality, food quality and physical environment had a positive effect on customer satisfaction.
\end{abstract}

Keyword: Restaurant quality, customer satisfaction.

Abstraks - Penelitian ini bertujuan untuk menguji pengaruh kualitas restoran terhadap kepuasan pelanggan. Subyek penelitian adalah pengunjung restoran Cengkir Heritage Resto and Coffe Yogyakarta. Penelitian ini mengembangkan suatu model teoritis dengan membuat tiga hipotesis yang akan diuji dengan menggunakan Structural Equation Model (SEM) melalui program aplikasi AMOS 18. Metode survei yang digunakan dalam penelitian ini adalah penyebaran kuesioner kepada 120 responden. Penelitian ini menggunakan teknik non-probability sampling, yaitu responden dipilih secara acak sesuai dengan tujuan penelitian. Hasil penelitian menunjukkan bahwa kualitas restoran yang terdiri dari kualitas pelayanan, kualitas makanan dan physical environment berpengaruh positif terhadap kepuasan pelanggan.

Kata kunci: Kualitas restoran, kepuasan pelanggan

\subsection{Latar Belakang}

Saat ini pariwisata telah menjadi industri andalan pemerintah untuk mendukung program pemerintah dalam hal pemasukan devisa negara dan pembangunan daerah. Pemerintah bekerjasama dengan pihak swasta untuk meningkatkan pariwisata dalam bidang perhotelan dan industri makanan dan minuman yaitu restoran, kedai kopi, cafe, rumah makan serta catering. Restoran merupakan tempat atau bangunan yang digunakan secara komersial untuk menyajikan pelayanan yang terbaik berupa makanan dan minuman kepada tamu yang datang (Marsum, 1994). Meningkatnya permintaan dan kebutuhan makanan dan minuman tidak terlepas dari pengaruh perubahan perilaku dan kemampuan masyarakat dalam mengelola bisnis kuliner. Akibat permintaan dan kebutuhan akan makanan dan minuman meningkat, sehingga mendorong pertumbuhan bisnis kuliner dari perkotaan sampai ke daerah pedalam dengan berbagai keunikan dan ciri khas masakan. Hal tersebut menjadikan restoran-restoran yang menyajikan keunikan dan menu-menu tradisional di Yogyakarta bertumbuh pesat seperti Cengkir Heritage Resto and Coffe yang melayani lebih dari 200 porsi makanan setiap harinya.
Cengkir Heritage Resto and Coffe adalah restoran yang menyajikan kuliner dengan menu masakan pedesaan khas Yogyakarta. Bentuk rumah makan ini dibuat seperti di desa dengan aksesoris dapur pedesaan seperti dandang, luweng dan lainlain. Restoran ini menggunakan sistem prasmanan (buffet), disajikan pada sebuah meja besar, lengkap dengan sayur, aneka lauk, dan sambal. Nasi disajikan terpisah dengan dandang yang masih terpasang diatas tungku kayu bakar. Menu makanan yang disajikan di Cengkir Heritage Resto and Coffe terdiri dari makanan khas jawa seperti sayur lodeh jantung pisang, sayur lompong, tempe lombok ijo, sop, tempe goreng, bakwan, telor dadar, ayam goreng, dan mangut lele. Tersedia juga makanan ringan seperti jadah bakar, pisang goreng dan mendoan. Minuman yang disajikan juga khas daerah Jawa, seperti wedang uwuh, jahe, kunyit asem, beras kencur, kopi cengkir, bir pletok, susu pletok, lemon tea, dan lain-lain. Cengkir Heritage Resto and Coffe memiliki konsumen yang berasal dari dalam dan luar negri, dan jumlah pengunjung di resto ini terbilang cukup banyak.

Konsumen di Cengkir Heritage Resto and Coffe pada umumnya menginginkan kualitas restoran yang bagus. Hubungan 
antara kualitas dan kepuasan konsumen akhirakhir ini menarik perhatian para peneliti. Penelitian terdahulu telah melakukan studi di beberapa tipe restoran yang berbeda untuk memeriksa dampak dari kualitas layanan terhadap kepuasan konsumen (Kanta dan Srivalli, 2014). Namun, hanya sedikit perhatian yang meneliti hubungan antara total kualitas retoran dengan kepuasan konsumen (Gagic et al, 2013). Penelitian ini menggunakan dimensidimensi kualitas restoran menurut Canny (2014), yaitu kualitas layanan, kualitas makanan, lingkungan (physical environment).

Kualitas pelayanan merupakan salah satu faktor penting dalam menentukan kepuasan konsumen. Menurut Tjiptono (2003) kualitas pelayanan adalah tingkat keunggulan yang diharapkan dan pengendalian atas tingkat keunggulan tersebut untuk memenuhi keinginan pelanggan. Kualitas pelayanan merupakan pelayanan kepada pelanggan dengan menyediakan produk atau jasa dalam rangka memenuhi kebutuhan, keinginan dan harapan pelanggan (Sugiarto, 1999). Saglik et.al (2014), mengatakan bahwa kualitas pelayanan sebuah restoran dibagi menjadi tiga dimensi, yaitu : layanan (service), kebersihan (hygiene) dan atmosfer (atmosphere). Penelitian ini menggunakan dimensi kualitas menurut Kotler (2007), yaitu tangibles, reliability, responsiveness, assurance, dan emphaty.

Kualitas makanan memiliki empat dimensi yaitu freshness, presentation, well cooked, dan variety of food (Malik et al.,2013). Freshness merupakan kesegaran makanan dalam hal tekstur, rasa dan aroma makanan. Presentation merupakan penyajian makanan yang disuguhkan kepada konsumen, yang berisikan komposisi yang telah diatur dan disesuaikan secara menarik agar dapat menambah nafsu makan. Well cooked merupakan makanan yang disajikan telah diolah dan dimasak terlebih dahulu dengan baik dan higienis sehingga aman dikonsumsi oleh konsumen. Variety of food merupakan keanekaragaman makanan suatu restoran, digambarkan dengan jumlah menu makanan yang berbeda yang ditawarkan oleh restoran kepada pelanggan.

Physical environment terdiri dari dua dimensi, yaitu external environment dan interior design (saraiva, et al.,2011). External environment mengarah kepada lokasi restoran, dan aksesibilitas orang-orang berkebutuhan khusus dan parkir. Sedangkan interior design mengarah kepada ukuran bangunan restoran, pengaturan meja makan, desain furniture dan kenyamanan (Pecotic, et al., 2014).
Kualitas restoran dianggap baik dan memuaskan jika restoran dapat memberikan jasa melalui harapan konsumen, jika jasa yang diberikan lebih rendah dari harapan konsumen, maka kualitas restoran dianggap buruk. Maka dari itu, kualitas yang baik dalam suatu usaha restoran, akan menciptakan kepuasan bagi para konsumennya. Jika konsumen merasa sangat puas, maka konsumen akan melakukan pembelian berulang sehingga terbangun rasa fanatik yang juga berakibat pada pembelian.

Kepuasan konsumen merupakan persepsi individual terhadap performa barang atau jasa yang berhubungan dengan ekspetasi pelanggan (Schiffman dan Kanuk, 2007). Menurut Irawan (2009), kepuasan pelanggan dapat memberikan kontribusi untuk aspekaspek krusial, seperti meningkatnya loyalitas pelanggan, terciptanya reputasi perusahaan, mengurangi elastisitas harga, serta bertumbuhnya efisiensi dan produktivitas tenaga kerja. Kotler dan Keller (2008) mengatakan bahwa kepuasan merupakan tingkat perasaan dimana seseorang menyatakan hasil perbandingan atas kinerja produk atau jasa yang diterima dengan yang diharapkan.

Hipotesis dalam penelitian ini adalah sebagai berikut :

1. H1: Kualitas pelayanan berpengaruh positif terhadap kepuasan pelanggan

2. H2: Kualitas makanan berpengaruh positif terhadap kepuasan pelanggan

3. H3: Physical environment berpengaruh positif terhadap kepuasan pelanggan

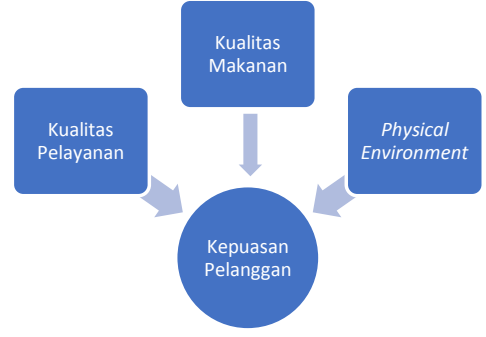

\section{Gambar 1. Model Penelitian}

\subsection{Metodologi Penelitian}

Penelitian ini dilakukan di Cengkir Heritage Resto and Coffe yang terletak di Jalan Sumberan II No.4, Sindurharjo, Sleman, DIY. Penelitian ini fokus pada kualitas makanan, kegiatan pelayanan, physical environment dan kualitas restoran. Data yang digunakan dalam penelitian ini adalah data primer. Metode yang digunakan dalam penelitian ini adalah metode survey dengan menggunakan kuesioner, dan meminta responden untuk mengisi kuesioner tersebut. Metode pemilihan sampel yang akan digunakan adalah non-probability sampling 
yang terdiri dari 120 orang dari seluruh pengunjung Cengkir Heritage Resto and Coffe Yogyakarta. Dalam penelitian ini, pengujian validitas menggunakan alat ukur analisis faktor dengan alat bantu program SPSS 18. Pengujian reliabilitas menggunakan SPSS 18 sebagai alat untuk menghitung nilai cronbach's alpha. Nilai cronbach's alpha dikategorikan sebagai berikut : 1) 0,8-1,0: reliabilitas baik, 2) 0,6-7,9: reliabilitas diterima, 3) $<0,6$ : reliabilitas buruk. Pengujian hipotesis dari $\mathrm{H} 1, \mathrm{H} 2$, dan $\mathrm{H} 3$ dilakukan menggunakan SEM dengan bantuan program Amos 16.0. Peneliti menggunakan SEM agar memberikan hasil yang tepat dalam analisis multivariat. Analisis multivariat dilakukan karena peneliti menggunakan variabel laten dalam penelitian ini, yaitu kepuasan konsumen sebagai variabel dependen, dan kualitas pelayanan, kualitas makanan dan physical environment sebagai variabel independen.

\subsection{HASIL DAN PEMBAHASAN}

Hasil pengujian validitas ditemukan bahwa 5 item pertanyaan pada variabel kualitas pelayanan valid, sehingga dapat digunakan pada pengujian hipotesis.

\section{Tabel 1}

Hasil Uji Validitas Variabel Kualitas Pelayanan

\begin{tabular}{|c|c|c|c|}
\hline Kode & $\begin{array}{c}\text { Item } \\
\text { Pertanyaan }\end{array}$ & $\begin{array}{l}\text { Factor } \\
\text { Loading }\end{array}$ & Status \\
\hline KP1 & $\begin{array}{l}\text { Kemampuan } \\
\text { dan keramahan } \\
\text { pegawai } \\
\text { restoran dalam } \\
\text { memberikan } \\
\text { pelayanan }\end{array}$ & 0.62 & Valid \\
\hline KP2 & $\begin{array}{l}\text { Daya tanggap } \\
\text { dan kecekatan } \\
\text { pegawai } \\
\text { restoran dalam } \\
\text { melayani } \\
\text { konsumen }\end{array}$ & 0.54 & Valid \\
\hline KP3 & $\begin{array}{l}\text { Perhatian/atensi } \\
\text { pegawai } \\
\text { restoran dalam } \\
\text { menanggapi } \\
\text { permintaan } \\
\text { konsumen }\end{array}$ & 0.62 & Valid \\
\hline KP4 & $\begin{array}{l}\text { Memberikan } \\
\text { jaminan } \\
\text { kemanan, dan } \\
\text { ganti rugi pada } \\
\text { layanan buruk } \\
\text { yang diberikan } \\
\text { pegawai } \\
\text { restoran kepada } \\
\text { pelanggan }\end{array}$ & 0.58 & Valid \\
\hline KP5 & $\begin{array}{l}\text { Memberikan } \\
\text { empati berupa } \\
\text { ucapan atau } \\
\text { bonus kepada }\end{array}$ & 0.56 & Valid \\
\hline
\end{tabular}

\begin{tabular}{|l|l|l|l|}
\hline & pelanggan & & \\
\hline
\end{tabular}

Hasil pengujian validitas ditemukan bahwa 5 item pertanyaan pada variabel kualitas pelayanan valid, sehingga dapat digunakan pada pengujian hipotesis.

Tabel 2

Hasil Uji Validitas Variabel Kualitas

Makanan

\begin{tabular}{|c|l|c|c|}
\hline Kode & Item Pertanyaan & $\begin{array}{c}\text { Factor } \\
\text { Loading }\end{array}$ & Status \\
\hline KM1 & $\begin{array}{l}\text { Makanan yang } \\
\text { disaikan selalu } \\
\text { segar dari segi } \\
\text { tekstur, rasa dan } \\
\text { aroma }\end{array}$ & 0.66 & Valid \\
\hline KM2 & $\begin{array}{l}\text { Makanan yang } \\
\text { disajikan memiliki } \\
\text { komposisi warna } \\
\text { yang menarik mata } \\
\text { dan menambah } \\
\text { nafsu makan }\end{array}$ & 0.62 & Valid \\
\hline KM3 & $\begin{array}{l}\text { Makanan yang } \\
\text { disaikan telah } \\
\text { diolah secara baik } \\
\text { dan higienis }\end{array}$ & 0.57 & Valid \\
\hline KM4 & $\begin{array}{l}\text { Restoran memiliki } \\
\text { menu makanan } \\
\text { yang bervariasi }\end{array}$ & 0.69 & Valid \\
\hline
\end{tabular}

Hasil pengujian validitas ditemukan bahwa 5 item pertanyaan pada variabel physical environment valid, sehingga dapat digunakan pada pengujian hipotesis.

Tabel 3

Hasil Uji Validitas Variabel Physical environment

\begin{tabular}{|c|l|c|c|}
\hline Kode & Item Pertanyaan & $\begin{array}{c}\text { Factor } \\
\text { Loading }\end{array}$ & Status \\
\hline PE1 & $\begin{array}{l}\text { Lokasi restoran } \\
\text { mudah ditemukan }\end{array}$ & 0.52 & Valid \\
\hline PE2 & $\begin{array}{l}\text { Restoran memiliki } \\
\text { lahan parkir yang } \\
\text { luas }\end{array}$ & 0.58 & Valid \\
\hline PE3 & $\begin{array}{l}\text { Restoran memiliki } \\
\text { akses jalan yang } \\
\text { mudah digunakan } \\
\text { untuk penyandang } \\
\text { disabilitas }\end{array}$ & 0.51 & Valid \\
\hline PE4 & $\begin{array}{l}\text { Restoran memiliki } \\
\text { ukuran bangunan } \\
\text { yang luas dan } \\
\text { menarik }\end{array}$ & 0.54 & Valid \\
\hline PE5 & $\begin{array}{l}\text { Restoran memiliki } \\
\text { desain furniture } \\
\text { yang menarik dan } \\
\text { nyaman }\end{array}$ & 0.53 & Valid \\
\hline
\end{tabular}

Tabel 4

Hasil Uji Validitas Variabel Kepuasan Pelanggan

\begin{tabular}{|l|l|l|l|}
\hline Kode & Item Pertanyaan & $\begin{array}{c}\text { Factor } \\
\text { Loading }\end{array}$ & Status \\
\hline
\end{tabular}




\begin{tabular}{|c|c|c|c|}
\hline KEP1 & $\begin{array}{c}\text { Tidak ada keluhan } \\
\text { dari pelanggan } \\
\text { terhadap pelayanan } \\
\text { yang diberikan oleh } \\
\text { restoran }\end{array}$ & 0.70 & Valid \\
\hline KEP2 & $\begin{array}{c}\text { Pelanggan merasa } \\
\text { nyaman saat } \\
\text { berada di restoran }\end{array}$ & 0.67 & Valid \\
\hline KEP3 & $\begin{array}{c}\text { Keinginan dan } \\
\text { harapan pelanggan } \\
\text { terpenuhi dengan } \\
\text { produk dan jasa } \\
\text { yang diberikan } \\
\text { restoran }\end{array}$ & 0.75 & Valid \\
\hline KEP4 & $\begin{array}{c}\text { Pelanggan loyal } \\
\text { dan memberikan } \\
\text { referensi yang baik } \\
\text { kepada orang lain }\end{array}$ & 0.59 & Valid \\
\hline
\end{tabular}

Setelah pengujian validitas, dilakukan pengujian reliabilitas pada data item pertanyaan yang valid menggunakan metode cronbach's alpha. Berdasarkan pengujian reliabilitas, ditemukan bahwa variabel kualitas makanan, kualitas pelayanan, physical environment, dan kepuasan pelanggan adalah reliabel. Tabel 4 menyajikan hasil output uji reliabilitas untuk variabel kualitas makanan, kualitas pelayanan, physical environment dan kepuasan pelanggan.

\section{Tabel 5}

Hasil Uji Reliabilitas

\begin{tabular}{|c|c|c|}
\hline Variabel & $\begin{array}{c}\text { Cronbach' } \\
\text { s alpha }\end{array}$ & Kategori \\
\hline $\begin{array}{c}\text { Kualitas } \\
\text { makanan }\end{array}$ & 0.77 & Reliabilitas baik \\
\hline $\begin{array}{c}\text { Kualitas } \\
\text { pelayanan }\end{array}$ & 0.82 & Reliabilitas baik \\
\hline $\begin{array}{c}\text { Physical } \\
\text { environment }\end{array}$ & 0.76 & Reliabilitas baik \\
\hline $\begin{array}{c}\text { Kepuasan } \\
\text { pelanggan }\end{array}$ & 0.88 & Reliabilitas baik \\
\hline
\end{tabular}

Pengujian hipotesis dari $\mathrm{H} 1, \mathrm{H} 2$ dan $\mathrm{H} 3$ diuji dengan menggunakan SEM (Standard Equation Model) dengan tujuan untuk melihat significant path pada penelitian. Hasil pengujian hipotesis dapat terlihat pada tabel 6 .

\section{Tabel 6}

Hasil Uji Hipotesis

\begin{tabular}{|c|l|c|c|c|}
\hline No & Hipotesis & $\begin{array}{c}\text { Standardized } \\
\text { Regression } \\
\text { Weights }\end{array}$ & P & Keterangan \\
\hline $\mathrm{H} 1$ & $\begin{array}{l}\text { Kualitas } \\
\text { pelayanan } \\
\text { berpengar } \\
\text { uh positif } \\
\text { terhadap } \\
\text { kepuasan } \\
\text { pelanggan }\end{array}$ & 0.356 & $<0.05$ & $\begin{array}{c}\text { Hipotesis } \\
\text { diterima }\end{array}$ \\
\hline $\mathrm{H} 2$ & $\begin{array}{l}\text { Kualitas } \\
\text { makanan } \\
\text { berpengar } \\
\text { uh positif } \\
\text { terhadap }\end{array}$ & 0.389 & $<0.05$ & $\begin{array}{c}\text { Hipotesis } \\
\text { diterima }\end{array}$ \\
\hline
\end{tabular}

\begin{tabular}{|c|c|c|c|c|}
\hline & $\begin{array}{l}\text { kepuasan } \\
\text { pelanggan }\end{array}$ & & & \\
\hline $\mathrm{H} 3$ & $\begin{array}{l}\text { Physical } \\
\text { environme } \\
\text { nt } \\
\text { berpengar } \\
\text { uh positif } \\
\text { terhadap } \\
\text { kepuasan } \\
\text { pelangaan }\end{array}$ & 0.297 & $<0.05$ & $\begin{array}{c}\text { Hipotesis } \\
\text { diterima }\end{array}$ \\
\hline
\end{tabular}

Penelitian ini telah dikembangkan untuk menguji pengaruh kualitas restoran terhadap kepuasan pelanggan. Berdasarkan pada beberapa dimensi dari kualitas restoran sebagai variabel independen, 3 hipotesis telah dihasilkan. Pada tabel 6 dapat dilihat bahwa kualitas pelayanan berpengaruh positif terhadap kepuasan pelanggan $(\beta=0.356$, $\mathrm{P}<0.05)$. Hasil analisis ini mendukung hipotesis pertama pada penelitian ini. Sehingga dapat diartikan bahwa, semakin baik kualitas pelayanan berdampak pada semakin meningkatnya kepuasan pelanggan. Hasil ini mendukung penelitian sebelumnya yang dilakukan oleh Tat et al (2011) yang mempelajari hubungan antara dimensi-dimensi kualitas pelayanan dengan kepuasan pelanggan.

Hipotesis kedua fokus kepada dimensidimensi kualitas makanan sebagai variabel independen, dan pada tabel 6 ditemukan bahwa kualitas makanan berpengaruh positif terhadap kepuasan pelanggan $(\beta=0.389$, $P<0.05)$. Hasil pengujian ini mendukung hipotesis kedua dalam penelitian ini. Sehingga dapat diartikan bahwa, semakin baik kualitas makanan akan meningkatkan kepuasan pelanggan. Hal ini mendukung penelitian yang telah dilakukan oleh Malik et al (2013) yang mempelajari pengaruh kualitas makanan dan kualitas pelayanan terhadap kepuasan pelanggan, serta penelitian yang dilakukan oleh Canny (2014) tentang dinning experience terhadap kepuasan pelanggan.

Hasil pengujian hipotesis pada penelitian ini juga mendukung hipotesis ketiga yaitu physical environment berhubungan positif dengan kepuasan pelanggan $(\beta=0.297$, $P<0.05)$. Hasil ini menunjukkan bahwa lingkungan yang baik secara eksterior dan interior dapat meningkatkan kepuasan pelanggan. Hal ini mendukung penelitian yang telah dilakukan oleh Saraiva et al (2011) tentang pengaruh external environment terhadap kepuasan pelanggan, dan penelitian Pecotic et al (2014) tentang pengaruh desain interior terhadap kepuasan pelanggan.

\subsection{Kesimpulan}

Berdasarkan hasil penelitian ini, Cengkir Heritage Resto and Coffe fokus pada faktor- 
faktor peningkatan kualitas untuk memelihara kepuasan pelanggan. Dimensi pertama yang memiliki pengaruh paling besar terhadap kepuasan pelanggan adalah kualitas makanan. Hal ini menunjukkan rasa, kesegaran makanan, kebersihan pengolahan makanan, presentasi makanan dan varian menu Cengkir Heritage Resto and Coffe menjadi hal yang paling diperhatikan pelanggan untuk membentuk persepsi mereka tentang kualitas restoran tersebut. Dimensi berikutnya yang memiliki pengaruh terbesar kedua adalah kualitas pelayanan. Hal ini berarti kualitas pelayanan Cengkir Heritage Resto and Coffe seperti kemampuan, keramahan, daya tanggap, perhatian dan empati merupakan faktor-faktor yang mampu mempengaruhi kepuasan pelanggan tapi tidak sebesar kualitas makanan restoran tersebut. Dimensi ketiga yang memiliki pengaruh paling kecil terhadap kepuasan pelanggan adalah physical environment. Meskipun eksterior dan interior bangunan Cengkir Heritage Resto and Coffe mempengaruhi kepuasan pelanggan, tetapi hal tersebut tidak menjadi perhatian utama pelanggan.

Penelitian ini telah menunjukkan hasil dari keseluruhan kualitas restoran Cengkir Heritage Resto and Coffe, tetapi hasil penelitian tidak dapat digeneralisasikan kepada seluruh tipe restoran. Maka dari itu, saran bagi penelitian selanjutnya untuk dapat menerapkan variabel yang sama menggunakan sampel yang lebih besar dari beberapa tipe restoran, agar hasil penelitian dapat digeneralisasikan dan diterapkan kepada seluruh tipe restoran.

\section{DAFTAR PUSTAKA}

[1] Canny, I. (2014), "Measuring the Mediating Role of Dining Experience Attributes on Customer Satisfaction and its Impact on Behavioral Intentions of Casual Dining Restaurant In Jakarta". International Journal of Innovation, Management and Technology, Vol 5, No.1, 25-29.

[2] Gagic, S., Tesanovic, D.,Jovicic, A. (2013), "The Vital Components of Restaurant Quality that Affect Guest Satisfaction. TURIZAM, Vol 17, No.4, 166-176.

[3] Irawan, H. (2009). 10 Prinsip Kepuasan Pelanggan. Jakarta: Elex Media Komputindo.
[4] Kanta, K., Srivalli, P. (2014), "A Study on Service Quality in Indian Restaurants with Decision and Experiential-Oriented Perspectives". International Journal of Research and Development- $A$ Management Review, Vol. 3, No.1, 16-24.

[5] Kotler, Philip. (2007). Manajemen Pemasaran. Terjemahan. Edisi 10. Jakarta: Erlangga.

[6] Kotler, Philip dan Kevin Lane Keller. (2008). Manajemen Pemasaran. Terjemahan. Edisi 13. Jakarta: Erlangga.

[7] Malik, H., Jaswal, L., Malik, S., Awan, T. (2013), "Measuring Service Quality Perceptions of The Customers of Restaurants in Pakistan". International Journal for Quality Research, Vol. 7, No.2, 187-200.

[8] Pecotic, M., Bazdan, V., Samardzija, J. (2014), "Interior Design in Restaurants as a Factor Influencing Customer Satisfaction". RIThink, 4, 10-14.

[9] Saglik, E., Gulluce, A., Kaya, U., Ozhan, C. (2014), "Service Quality and Customer Satisfaction Relationship: A Research in Erzurum Ataturk University Refectory". American International Journal of Contemporary Research, Vol. 4, No.1, 100-117.

[10] Saraiva, M., Cid, M., Baiao, C. (2011), "The Degree of Customer Satisfaction in University Restaurants: The case of the University of Evora in Portugal". Proceedings of EDULEARN 11 Conference, 4-6 July 2011, Barcelona, Spain.

[11] Schiffman, Leon. G dan Leslie Lazar Kanuk. (2007). Perilaku Konsumen. Edisi ke-7, Penerbit Diterjemahkan oleh Zoelkifi Kasip.Jakarta. PT. Indeks.

[12] Sugiarto, E. (1999). Psikologi Pelayanan Dalam Industri Jasa. Jakarta. PT. Gramedia Pustaka Utama.

[13]Tat, H., Sook-Min, S., Ai-Chin, T., Rasli, A., Hamid, A.A. (2011), "Consumer's Purchase Intention in Fast Food Restaurants: An Empirical Study on Undergraduate Students". The Special Issue on Contemporary Issues in Business and Economics, 2(5), 214-221.

[14]Tjiptono, F. (2003). Prinsip-Prinsip Total Quality Service. Yogyakarta. Andi.

[15]WA, Marsum (1994). Restoran dan Segala Permasalahannya. Yogyakarta, Andi. 